\title{
Comparison of the initial errors most likely to cause a spring predictability barrier for two types of El Niño events
}

\author{
Ben $\operatorname{Tian}^{1,2} \cdot$ Wansuo Duan ${ }^{2,3}$
}

Received: 29 December 2014 / Accepted: 7 October 2015 / Published online: 19 October 2015

(C) The Author(s) 2015. This article is published with open access at Springerlink.com

\begin{abstract}
In this paper, the spring predictability barrier (SPB) problem for two types of El Niño events is investigated. This is enabled by tracing the evolution of a conditional nonlinear optimal perturbation (CNOP) that acts as the initial error with the biggest negative effect on the El Niño predictions. We show that the CNOP-type errors for central Pacific-El Niño (CP-El Niño) events can be classified into two types: the first are CP-type-1 errors possessing a sea surface temperature anomaly (SSTA) pattern with negative anomalies in the equatorial central western Pacific, positive anomalies in the equatorial eastern Pacific, and accompanied by a thermocline depth anomaly pattern with positive anomalies along the equator. The second are, CP-type-2 errors presenting an SSTA pattern in the central eastern equatorial Pacific, with a dipole structure of negative anomalies in the east and positive anomalies in the west, and a thermocline depth anomaly pattern with a slight deepening along the equator. CP-type-1 errors grow in a manner similar to an eastern Pacific-El Niño (EP-El Niño) event and grow significantly during boreal spring, leading to a significant SPB for the CP-El Niño. CP-type-2 errors initially present as a process similar to a La Niñalike decay, prior to transitioning into a growth phase of an EP-El Niño-like event; but they fail to cause a SPB.
\end{abstract}

Wansuo Duan

duanws@lasg.iap.ac.cn

1 Laboratory for Climate Studies, National Climate Center, China Meteorological Administration, Beijing 100081, China

2 LASG, Institute of Atmospheric Physics, Chinese Academy of Sciences, Beijing 100029, China

3 Ningbo Collaborative Innovation Center of Nonlinear Harzard System of Ocean and Atmosphere, Ningbo University, Ningbo 315211, China
For the EP-El Niño events, the CNOP-type errors are also classified into two types: EP-type-1 errors and 2 errors. The former is similar to a CP-type-1 error, while the latter presents with an almost opposite pattern. Both EP-type-1 and 2 errors yield a significant SPB for EP-El Niño events. For both CP- and EP-El Niño, their CNOP-type errors that cause a prominent SPB are concentrated in the central and eastern tropical Pacific. This may indicate that the prediction uncertainties of both types of El Niño events are sensitive to the initial errors in this region. The region may represent a common sensitive area for the targeted observation of the two types of El Niño events.

Keywords El Niño events · Initial error · Spring predictability barrier

\section{Introduction}

El Niño-Southern Oscillation (ENSO) events are characterized by an inter-annual variation of the sea surface temperature (SST) over the tropical Pacific. They have received considerable attention for both their climatic and economic effects (Rasmusson and Carpenter 1982; Barber and Chavez 1983; Cane 1983; Rasmusson and Wallace 1983). During the last few decades, significant progress has been achieved in ENSO theories and predictions. However, considerable uncertainties still exist in realistic ENSO predictions (Jin et al. 2008; Luo et al. 2008). In particular, the so-called spring predictability barrier (SPB) encountered in ENSO forecasting contributes to the prediction uncertainty. It manifests as an apparent drop in ENSO prediction skill in April and May (Webster and Yang 1992; McPhaden 2003; Yu and Kao 2007). From perspective of error growth, the SPB referred to here is the phenomenon that ENSO 
forecasting has a large prediction error; in particular, a prominent error growth occurs during the spring when the prediction is made before the spring (Yu et al. 2009; Duan et al. 2009).

SPB exists in dynamical as well as statistical models, and their cause is hotly debated. Many studies have investigated this phenomenon (Webster and Yang 1992; Latif et al. 1994; Webster 1995; Samelson and Tziperman 2001; Xue et al. 1994; Fan et al. 2000; McPhaden 2003; Yu and Kao 2007; Mu et al. 2007a, b; Duan et al. 2009; Yu et al. 2009). Quite a few studies have emphasized the role of initial errors and suggested that the prediction skill of ENSO bestriding spring can be greatly enhanced through improving initialization (Chen et al. 1995, 2004). Moore and Kleeman (1996), Xue et al. (1997), and Mu et al. (2007a) all explored the season-dependent evolutions of initial errors related to the SPB; in particular, Mu et al. (2007b) demonstrated the role of initial error with a particular structure in yielding a SPB and suggested that it may be a result of the combined effect of three factors. These are the climatological annual cycle, El Niño itself, and the initial error of the particular pattern. So, although the climatological annual cycle is faithfully retained in models, a SPB can be still caused by the other factors. Mu et al. (2007b) and Yu et al. (2009) used the Zebiak-Cane model (Zebiak and Cane 1987) and identified the initial errors causing a significant SPB for El Niño events most probably by using the conditional nonlinear optimal perturbation approach (CNOP; $\mathrm{Mu}$ et al. 2003). Such initial errors were of CNOP's structure and also recognized in the initial analysis fields of realistic ENSO predictions (Duan and Wei 2012). Therefore, if these initial errors of CNOP's structure can be filtered from the initial analysis fields, ENSO forecast skill may be greatly improved.

The studies mentioned above paid attention to "traditional" El Niño events, i.e. the eastern Pacific-El Niño (EP-El Niño; Rasmusson and Carpenter 1982) with a warm SST centered in the eastern Pacific, while little is known about the SPB relative to the central Pacific-El Niño (CPEl Niño), which has a warm SST concentrated in the central Pacific (Ashok et al. 2007; Kao and Yu 2009; Kug et al. 2009). It has been demonstrated that EP-El Niño events became less frequent and CP-El Niño events more common during the late twentieth century, especially after the 1990s. CP-El Niño events significantly influence the temperature and precipitation over many parts of the globe but in a manner different from that of EP-El Niño events (see e.g. Weng et al. 2007). It is therefore necessary to study the predictability of CP-El Niño events, and to clarify the differences between the predictability dynamics of CP-El Niño and EP-El Niño events.

Although interest in the two types of El Niño events has recently increased, simulating and predicting the $\mathrm{CP}-\mathrm{El}$
Niño, in contrast to EP-El Niño, remains a challenge. The existence of model errors is an important impact factor (Kug et al. 2010; Kim et al. 2012; Hendon et al. 2009; Lim et al. 2009; Jeong et al. 2012; Duan et al. 2014). In fact, most models tend to reproduce only a single type of El Niño (Ham and Kug 2012). Moreover, they often have limited skill in predicting the CP-El Niño. Hendon et al. (2009) had limited success in predicting differences between the two El Niño types using the Australian Bureau of Meteorology's Predictive Ocean Atmosphere Model for Australia (POAMA) coupled seasonal forecast model. The effective prediction skill could hold only 1 month ahead. Even though an ensemble forecast technique was used to predict two types of El Niño events, Jeong et al. (2012) found that useful prediction skill was possible with a 4 months lead time.

Predictability studies may provide useful information on improving the forecast skill of both types of El Niño events. In this paper, we investigate the initial errors that cause a SPB for both types of El Niño events, and compare them to obtain useful information for improving the model forecast skill. Duan et al. (2014) proposed an approach of optimal forcing vector (OFV; see "Appendix"), which was superimposed to the tendency equation of the Zebiak-Cane model (Zebiak and Cane 1987) and corrected the model simulation closest to the observations. In this way, they reproduced the two types of El Niño events with the help of observational data. These reproduced El Niño events therefore provide a platform for predictability studies. Based on the reproduced two types of El Niño events, we conduct predictability experiments and identify the most perturbing initial errors associated with the SPB phenomenon. We attempt to address the following questions: whether or not the prediction errors of tropical sea surface temperature anomaly (SSTA) induced by the initial errors exhibit season-dependent evolution, associated with SPB for CP-El Niño events, similar to those for EP-El Niño events ( $\mathrm{Yu}$ et al. 2009); what is the difference between initial errors that are most likely to cause a significant SPB for CP- and EP-El Niño events; and whether the initial errors associated with a SPB have any implications for improving the forecast skill of the two types of El Niño events.

The remainder of this paper is organized as follows. We first introduce the ENSO model and the El Niño events reproduced by the OFV. We briefly review the ideas of CNOP in Sect. 3. Focusing on the SPB phenomenon for tropical Pacific SSTAs, CNOP-type errors for CP and EP-El Niño are presented in Sect. 4. Furthermore, the seasonal variation and dynamical mechanism of error growth related to the SPB are demonstrated. Section 5 is a discussion of our results, where we compare the growth behavior of CNOP-type errors to those of the signals for the two types of El Niño events, and further reveal the possible 
sensitive area for targeted observation of the two types of El Niño events. Finally, a summary is provided in Sect. 6.

\section{Reproducing eastern and central Pacific El Niño events with the Zebiak-Cane model}

The Zebiak-Cane model was the first coupled oceanatmosphere model to simulate the observed ENSO interannual variability, and has provided a benchmark in ENSO studies for decades (Zebiak and Cane 1987; Blumenthal 1991; Xue et al. 1994; Chen et al. 2004; Tang et al. 2008). The model is composed of a Gill-type steady-state linear atmospheric model and a reduced-gravity oceanic model, which depict the thermodynamics and dynamics of the tropical Pacific with oceanic and atmospheric anomalies near the mean climatological state specified from observations. The Zebiak-Cane model has been widely used to study ENSO dynamics and predictability, but these studies focused on EP-El Niño events (e.g. Chen et al. 2004; Chen and Cane 2008). There are fewer studies using the ZebiakCane model to simulate CP-El Niño events, mostly due to the effect of model errors characterized by cold tongue cooling and resultant systematic westward shift of the maximum variability of tropical Pacific SST associated with ENSO.
Duan et al. (2014) added an optimal tendency perturbation named OFV to the SST tendency equation by assimilating the Hadley Center Global Sea Ice and Sea Surface Temperature (HadISST) analyses data (Rayner et al. 2003) and reduced a model bias of climatological SST coldtongue cooling mode, finally obtaining simulation of three CP-El Nino events: 1990/1991, 2002/2003, 2004/2005. Although Duan et al. (2014) also superimposed an optimal tendency perturbation to correct the Zebiak-Cane model and obtain simulations of the EP-El Nino events $1982 / 1983$, 1987/1988 and 1997/1998, the model bias described by OFV is negligible and initial conditions play a dominant role in simulating EP-El Nino events. In any case, three EP- and three CP-El Nino events have been reproduced by the Zebiak-Cane model but perturbed by an OFV tendency perturbation (Figs. 1,2). The subsequent predictability experiments are based on these EP- and CP-El Niño events. So hereafter the so-called Zebiak-Cane model is referred to the Zebiak-Cane model with OFV tendency perturbation.

\section{Conditional nonlinear optimal perturbation}

The "SPB" phenomenon refers to as that ENSO forecasting has a large prediction error accompanied by a prominent
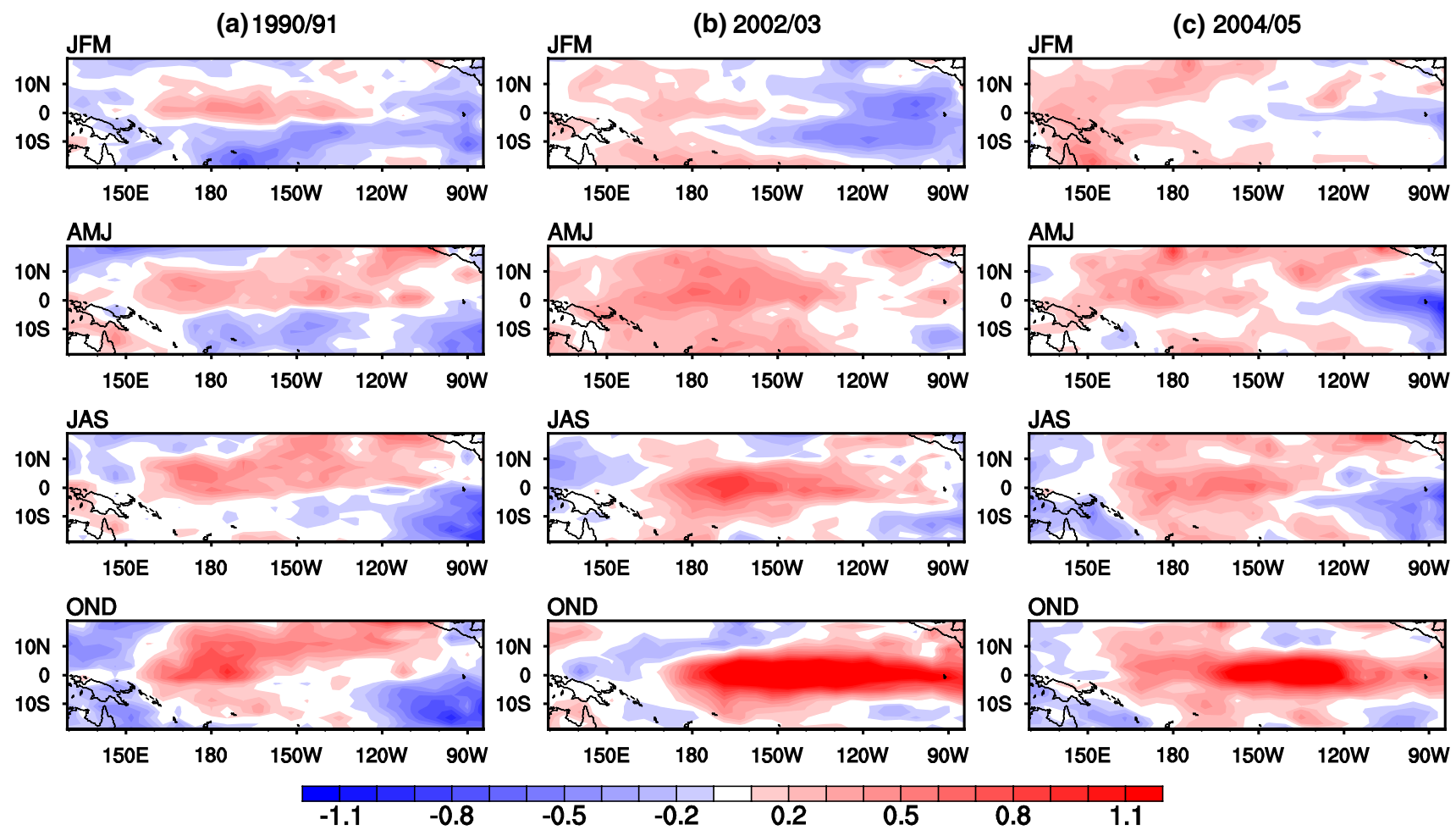

Fig. 1 The tropical SSTA of the reproduced CP-El Niño events (units are ${ }^{\circ} \mathrm{C}$ ) in different seasons. The CP-El Niño events are arranged by columns: a 1990/1991, b 2002/2003, and c 2004/2005 

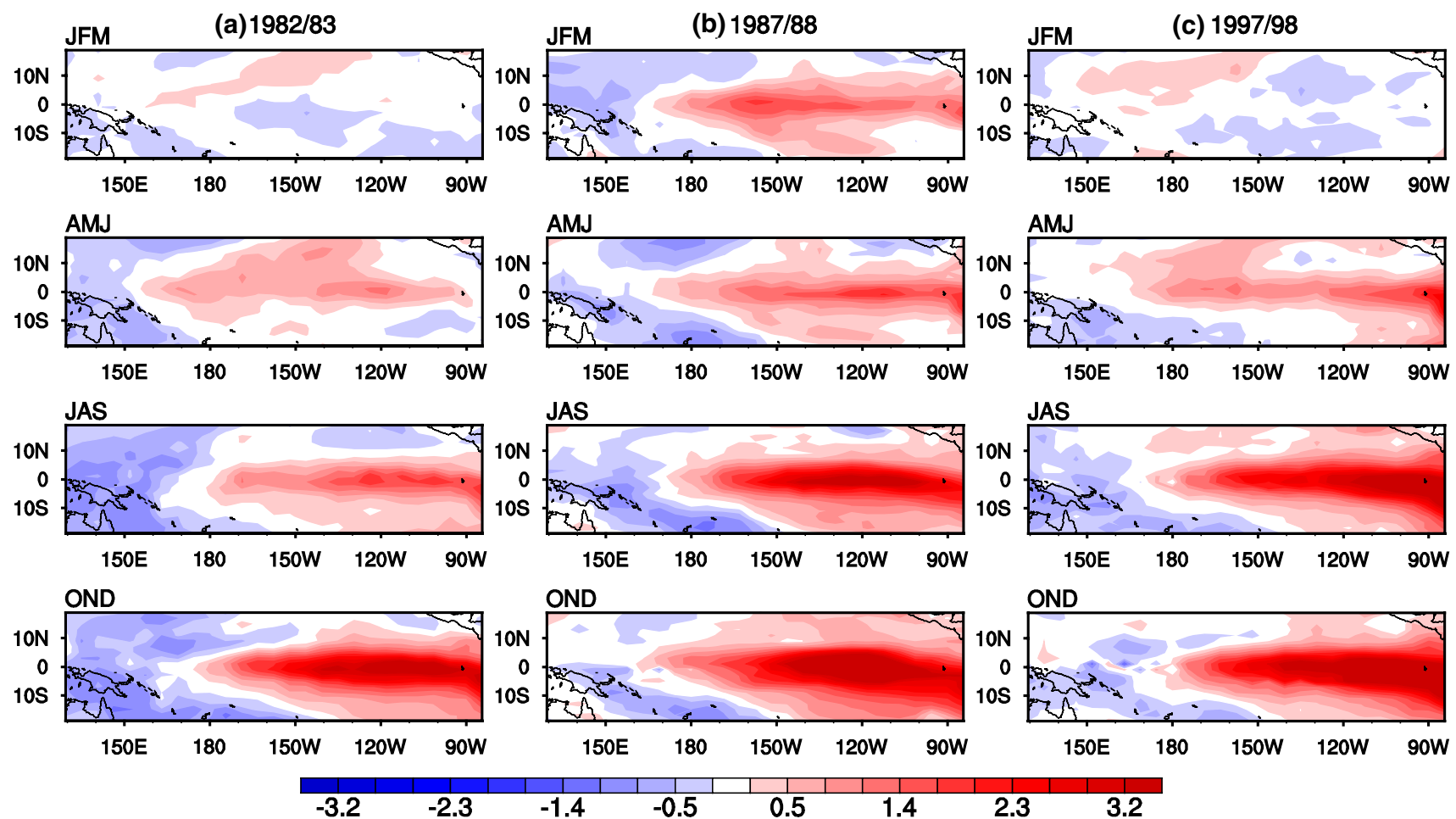

Fig. 2 The tropical SSTA component of the reproduced EP-El Niño events (units are ${ }^{\circ} \mathrm{C}$ ) in different seasons. The EP-El Niño events are in columns of a 1982/1983, b 1987/1988 and c 1997/1998

error growth during the spring when the prediction is made before the spring (Mu et al. 2007a; Yu et al. 2009; Duan et al. 2009; Duan and Wei 2012). CNOP represents the initial error that causes the largest prediction error at a prediction time most likely to yield a significant SPB for El Niño events (Mu et al. 2003, 2007b). In this paper, we use the CNOP approach to study the initial errors that cause a significant SPB most probably for two types of El Niño events.

The CNOP approach has already been applied to studies of ENSO predictability (Duan et al. 2004; Mu et al. 2007a, b; Yu et al. 2009, 2012). The approach has especially been used to explore the initial errors that cause a significant SPB for EP-El Niño events, despite the El Niño events concerned being model El Niño events (Yu et al. 2009, 2012). These studies illustrate that CNOP is a useful tool for predictability studies and that it is reasonable to use it to address initial errors associated with the SPB for CP-El Niño events.

The CNOP approach may be summarized as follows. Let $M_{t_{0}, t}$ be the propagator (i.e. the numerical model) of a nonlinear model from an initial time, $t_{0}$, to a time, $t$. An initial perturbation, $u_{0}$, is superimposed on the basic state $U(t)$. This is a solution to the nonlinear model, and satisfies $U(t)=M_{t}\left(U_{0}\right)$, where $U_{0}$ is the initial value of the basic state, $U(t)$.
For a chosen norm $\|\cdot\|$, an initial perturbation, $u_{0 \delta}$, is a CNOP if and only if:

$J\left(u_{0 \delta}\right)=\max _{\left\|u_{0}\right\| \leq \delta}\left\|M_{t_{0}, t}\left(U_{0}+u_{0}\right)-M_{t_{0}, t}\left(U_{0}\right)\right\|$,

where $\left\|u_{0}\right\| \leq \delta$ is the initial constraint defined by the chosen norm $\|\cdot\|$. The norm $\|\cdot\|$ also measures the evolution of the perturbation. We can also investigate a situation in which the initial perturbation belongs to another kind of functional set. Furthermore, the constraint condition could reflect physical laws that the initial perturbation should satisfy.

CNOP is the initial perturbation whose nonlinear evolution attains the maximum value of the cost function, $J$, at time, $\tau$ (Mu et al. 2003; Mu and Zhang 2006). To compute the CNOP, one needs to solve the maximization problem in Eq. (1). To do this, we transform Eq. (1) into a minimization problem by considering the negative of the cost function. This way, minimization solvers such as the spectral projected gradient 2 (SPG2; Birgin et al. 2000), sequential quadratic programming (SQP; Powell 1982), or the Limited Memory Broyden-Fletcher-Goldfarb-Shanno method (L-BFGS; Liu and Nocedal 1989) can be used to compute the CNOP. In these solvers, the gradient of the modified cost function is necessary, and the adjoint of the corresponding model is usually used to obtain the gradient. With 
this gradient information, running these solvers with initial guesses can find the minimum of the modified cost function-i.e. the maximum of the cost function in Eq. (1) along the descending direction of the gradient. In phase space, the point corresponding to the minimum of the modified cost function is the CNOP defined by Eq. (1). In this paper, we use the SPG2 solver to obtain the CNOPs of the Zebiak-Cane model. To obtain a CNOP, we try at least 30 randomly generated initial guesses; if there exist several initial guesses that converge to a point in phase space, and then this point is considered a minimum in a neighborhood. Thus, several such points are obtained. Of these points, the one that best maximizes the cost function in Eq. (1) is taken as the CNOP.

In the Zebiak-Cane model, the aforementioned CNOP, $\vec{u}_{0 \delta}$, can be obtained by solving the following nonlinear optimization problem:

$J\left(\vec{u}_{0 \delta}\right)=\max _{\left\|\vec{u}_{0}\right\|_{2} \leq \delta}\left\|T^{\prime}(\tau)\right\|_{2}$,

where $\vec{u}_{0}=\left(w_{1} \vec{T}_{0}^{\prime}, w_{2} \vec{H}_{0}^{\prime}\right) ; \vec{T}_{0}^{\prime}$ and $\vec{H}_{0}^{\prime}$ are the initial errors of SSTA and thermocline depth anomaly that superposed on the initial fields of the El Niño events simulated by the Zebiak-Cane model; $w_{1}=\left(2.0^{\circ} \mathrm{C}\right)^{-1}$ and $w_{2}=(50 \mathrm{~m})^{-1}$ are the characteristic scales of SST and thermocline depth; $\left\|\vec{u}_{0}\right\|_{2} \leq \delta$ is the constraint condition defined by a prescribed positive real number, $\delta$, and the norm $\left\|\vec{u}_{0}\right\|_{2}=\sqrt{\sum_{i, j}\left\{\left(w_{1} T_{0 i, j}^{\prime}\right)^{2}+\left(w_{2} H_{0 i, j}^{\prime}\right)^{2}\right\}}$, where $(i, j)$ represents the grid point in the tropical Pacific region from $129.375^{\circ} \mathrm{E}$ to $84.375^{\circ} \mathrm{W}$ by 5.625 and from $19^{\circ} \mathrm{S}$ to $19^{\circ} \mathrm{N}$ by 2 ; and $T_{0 i, j}^{\prime}$ and $H_{0 i, j}^{\prime}$ denote the dimensional initial errors of SSTA and thermocline depth anomaly at the grid point $(i, j)$. The evolutions of these initial errors are measured by the norm $\left\|\vec{T}^{\prime}(\tau)\right\|_{2}=\sqrt{\sum_{i, j} w_{1} T_{i, j}^{\prime}(\tau)}$. Specifically, the prediction errors, $\vec{T}_{i, j}^{\prime}(\tau)$, in the domain of the tropical Pacific are obtained by subtracting the SSTA of the "true" state (i.e. the El Niño events simulated by the Zebiak-Cane model with OFV) from the predicted SSTA at a prediction time, $\tau$.

\section{The conditional nonlinear optimal perturbation-type initial errors for eastern and central Pacific El Niño events and the related spring predictability barrier}

As mentioned in Sect. 2, three CP- and three EP-El Niño events are chosen to address the season-dependent evolution of initial errors associated with a SPB for two types of El Niño events. For each El Niño event, we make predictions 1 year ahead with the starting months January
(0), April (0), July (0), and October (0), with initial errors superimposed on the states of El Niño at the start months, where " 0 " denotes the year when El Niño attains a peak value. For example, for 1990/1991 El Niño event, four forecast experiments were initialized in January, April, July and October of the year 1990 and then run for 1 year. The initial errors are constrained by $\left\|\vec{u}_{0}\right\|_{2} \leq \delta$ with $\delta=1.5$, derived from realistic analysis data and implying that the initial SSTA errors do not exceed $0.2{ }^{\circ} \mathrm{C}$ in any grid cell and the thermocline depth anomaly errors are less than $2 \mathrm{~m}$ (Yu et al. 2012). Thus, for each El Niño event, there are 4 predictions, leading to a total number of 12 predictions for the three EP-El Niño events and 12 predictions for the three CP-El Niño events. For each prediction of an El Niño event, we calculate the CNOP-type initial errors using the strategy in Sect. 3, which cause the largest prediction errors for tropical Pacific SSTA associated with the two types of El Niño events and have the potential to induce a significant SPB.

To investigate the seasonal evolution of prediction errors caused by the CNOP-type initial errors, a year is divided into four seasons: January to March (JFM), April to June (AMJ), and so forth. The SPB phenomenon is then studied by investigating the seasonal tendency of initial error growth, measured by the slope $(\kappa)$ of the curve, $\gamma(t)=\left\|T^{\prime}(t)\right\|_{2}$, for different seasons. Here $\vec{T}^{\prime}(t)$ is the same as in Sect. 3, and represents the SSTA component of the prediction errors caused by initial errors. A positive value of $\kappa$ corresponds to an increase of the errors, and the larger the absolute value of $\kappa$, the faster the increase, and vice versa.

\subsection{Central Pacific-El Niño events}

For the three reproduced CP-El Niño events 1990/1991, 2002/2003, 2004/2005, we calculate the CNOP-type initial errors superimposed on the tropical SSTA and thermocline depth anomaly for the start times January (0), April (0), July (0), and October (0), respectively. When the start months are January (0) and April (0), the CNOP-type initial errors often exhibit an SSTA component with a zonal dipolar pattern, with negative anomalies in the central western equatorial Pacific and positive anomalies in the eastern equatorial Pacific, and a consistently deepened thermocline depth across the equatorial Pacific (see Fig. 3a). However, when the start months are July (0) and October (0), an SSTA pattern in the central eastern equatorial Pacific is seen, with a dipole structure of negative anomalies in the eastern and positive anomalies in the western parts, and a thermocline depth anomaly pattern deepening slightly along the equator. Hence, the CNOP-type initial errors for CP-El Niño events can be classified into two types. To facilitate this description, we denote the former as a CPtype- 1 error, and the latter as a CP-type- 2 error. Figure 3 
SST Anomaly

\section{SST}

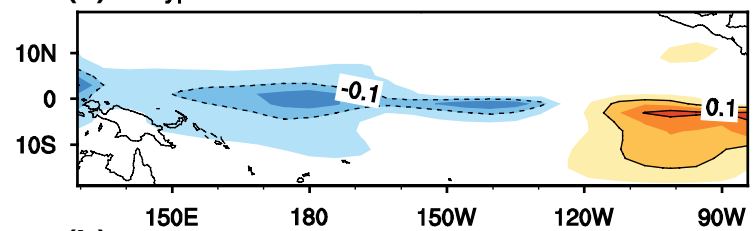

(b) CP-type-2 CNOP error

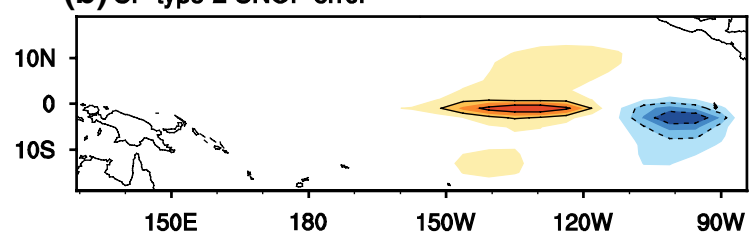

Fig. 3 Composite of a CP-type-1 and b CP-type-2 CNOP errors of the three CP-El Niño events. The left column is the SSTA component (units are ${ }^{\circ} \mathrm{C}$; the contour interval is $0.1{ }^{\circ} \mathrm{C}$ ), and the right column is
Thermocline Depth Anomaly
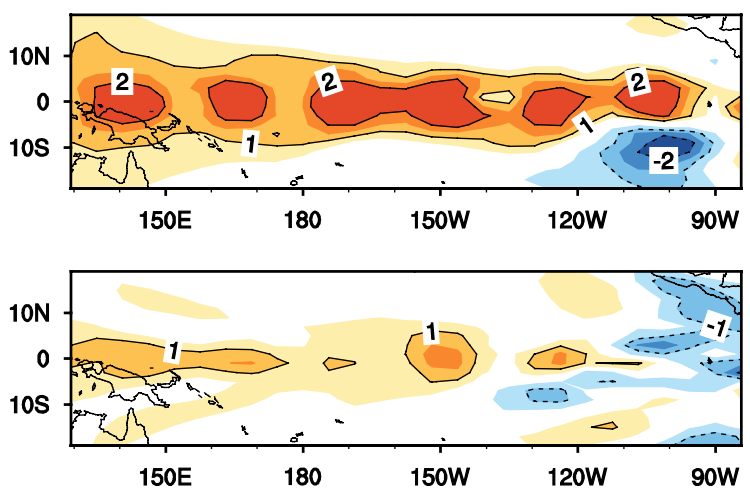

the thermocline depth anomaly component (units are m; the contour interval is $1.0 \mathrm{~m}$ ) (a) $1990 / 91$

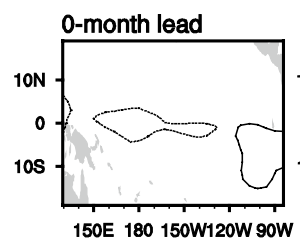

3-month lead

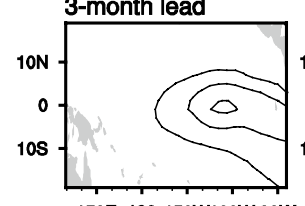

150E 180 150W120W 90W 6-month lead

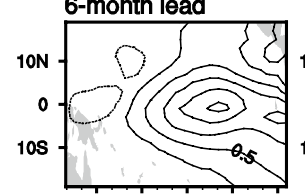

150E 180 150W120W 90W 9-month lead

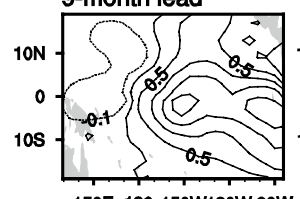

150E 180 150W120W 90W 12-month lead
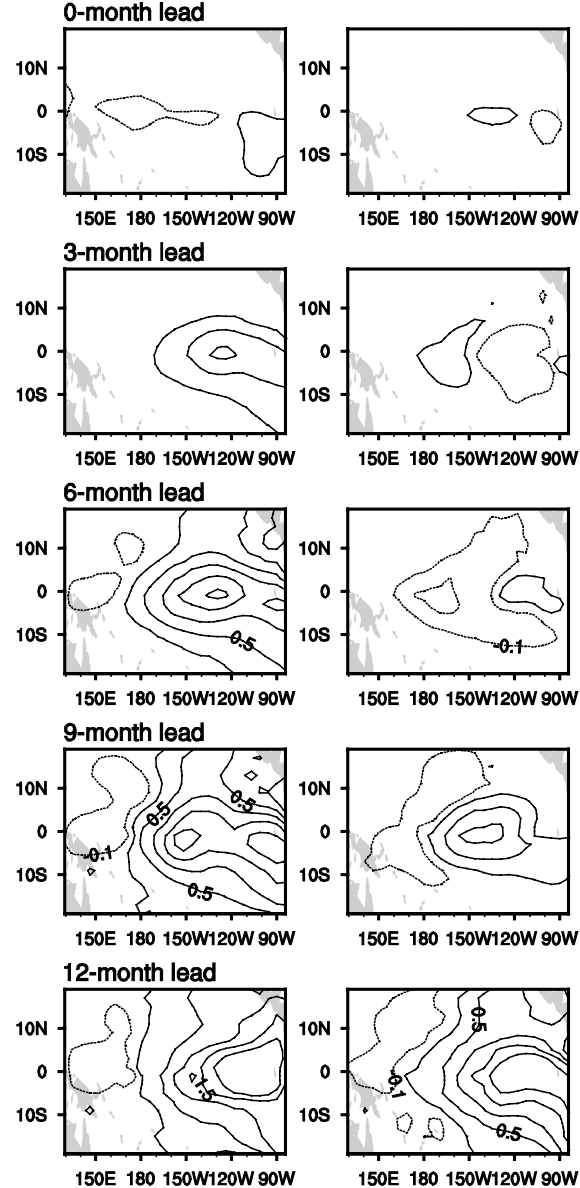

150E 180 150W120W 90W

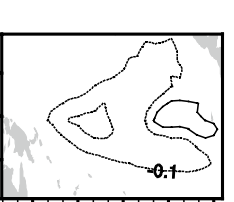

150E 180 150W120W 90W

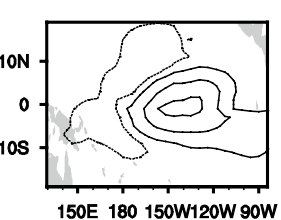

I50E 180 150W120W 90W

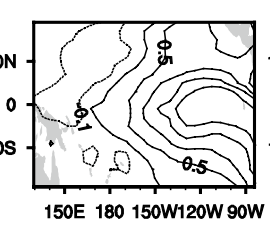

(b) $2002 / 03$

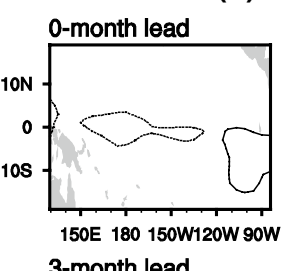

3-month lead

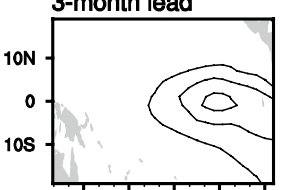

150E 180 150W120W 90W 6-month lead

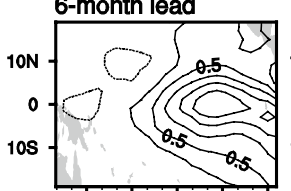

150E 180 150W120W 90W 9-month lead

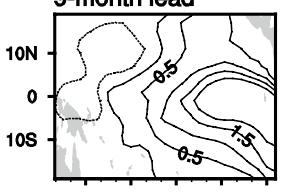

150E 180 150W120W 90W 12-month lead

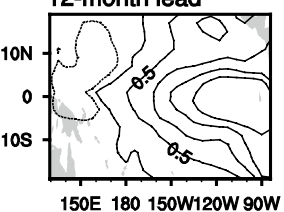

150E 180 150W120W 90W

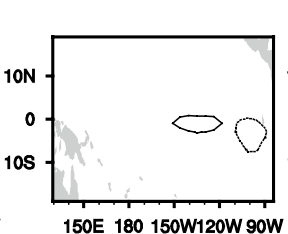
0-month lead

(c) $2004 / 05$
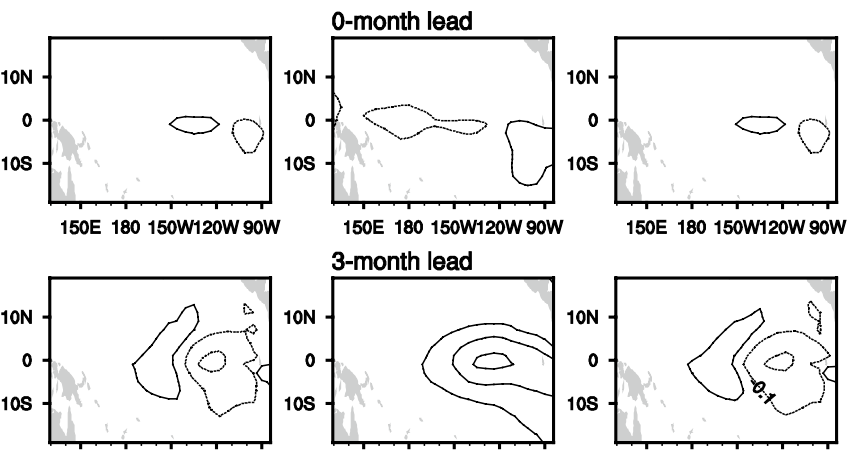

3-month lead
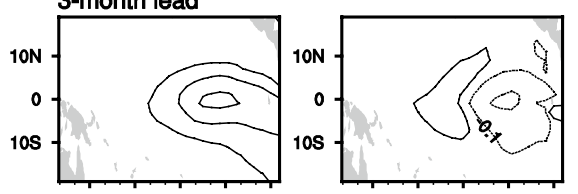

I50E 180 150W120W 90W

150E 180 150W120W 90W

150E 180 150W120W 90W
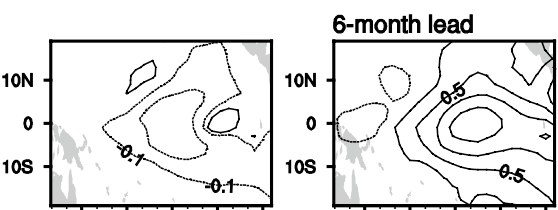

150E 180 150W120W 90W

9-month lead
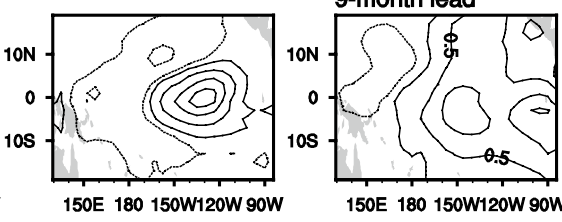

150E 180 150W120W 90W

12-month lead
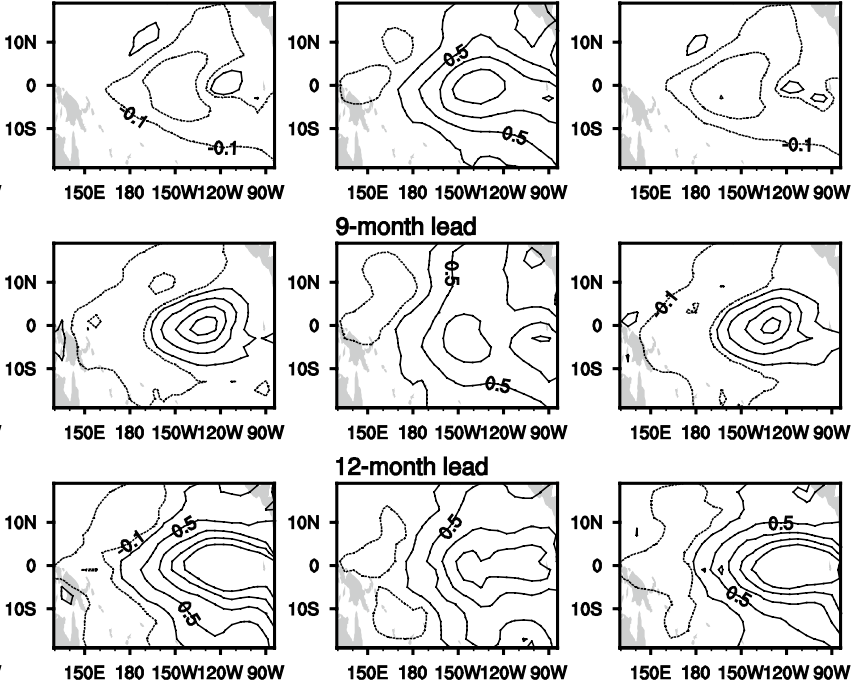

150E 180 150W120W 90W

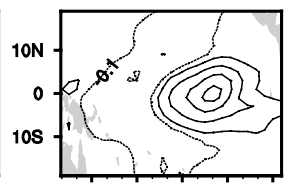

50E 180 150W120W 90W

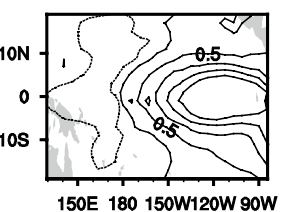

Fig. 4 Composite of the SSTA component of prediction errors caused by the CP-type- 1 and CP-type- 2 errors, superimposed on three CP-El Niño events: a 1990/1991, b 2002/2003, and c 2004/2005. For each El Niño event, the left column shows the composite of predic- tion errors with start months being January (0), April (0), July (0) and October (0) caused by CP-type- 1 errors while the right column illustrates those caused by $\mathrm{CP}$-type- 2 errors (units: ${ }^{\circ} \mathrm{C}$ ) 
shows a composite of the CP-type- 1 and 2 errors for the three CP-El Niño events.

To explore the growth dynamical behaviors for CP-type-1 and -2 errors, we integrate the Zebiak-Cane model for 1 year with the perturbed initial fields at start months (initial time of predictions) of January (0), April (0), July (0), and October (0). The perturbed initial fields referred to here are constructed by the initial value of each reproduced CP-El Niño event plus the CP-type-1 errors and CP-type-2 errors shown in Fig. 3, although the CP-type-1 errors are obtained by the start months January (0) and April (0) and the CPtype-2 errors are resulted from July (0) and October (0). Then we obtain two predictions for each start month of an El Nino event: one is the prediction with initial fields being initial values of CP-El Nino event plus CP-type-1 errors; the other is the prediction with initial fields as initial values of CP-El Nino event plus CP-type-2 errors. By subtracting the reproduced CP-El Niño events from the predictions, there obtain the prediction errors caused by the CP-type- 1 and 2 errors for CP-El Niño events. Figure 4 shows a composite of the SSTA component of prediction errors caused by the CPtype-1 and CP-type-2 errors for three CP-El Niño events. By observing the evolution of the prediction errors, we find that the CP-type-1 error, whichever start month the predictions are initialized at, often has an evolving mode, similar to the growth phase of an EP-El Niño-like event; while the CP-type-2 error tends to initially experience a process similar to a La Niña-like decay prior to a transition to the growth phase of an EP-El Niño-like event. All these indicate that the CP-type- 1 and 2 errors tend to cause CP-El Niño to have an EP-El Niño-like evolving mode. That is to say, the CP-El Niño events are inclined to be predicted into EP-El Niño events due to effect of CP-type-1 and -2 errors. Specifically, we show in Fig. 5 the predicted SSTA of January of 1991, 2003 and 2005 initialized in January of 1990, 2002, 2004, respectively, with CP-type- 1 and -2 errors. Thus, the January SSTA of 1991, 2003, and 2005 in Fig. 5 show the predictions for the three CP-El Niño events 1990/1991, 2002/2003, 2004/2005. It is illustrated that the CP-type-1 and -2 errors tend to make the predicted SSTA locate in the (a) $1990 / 91$
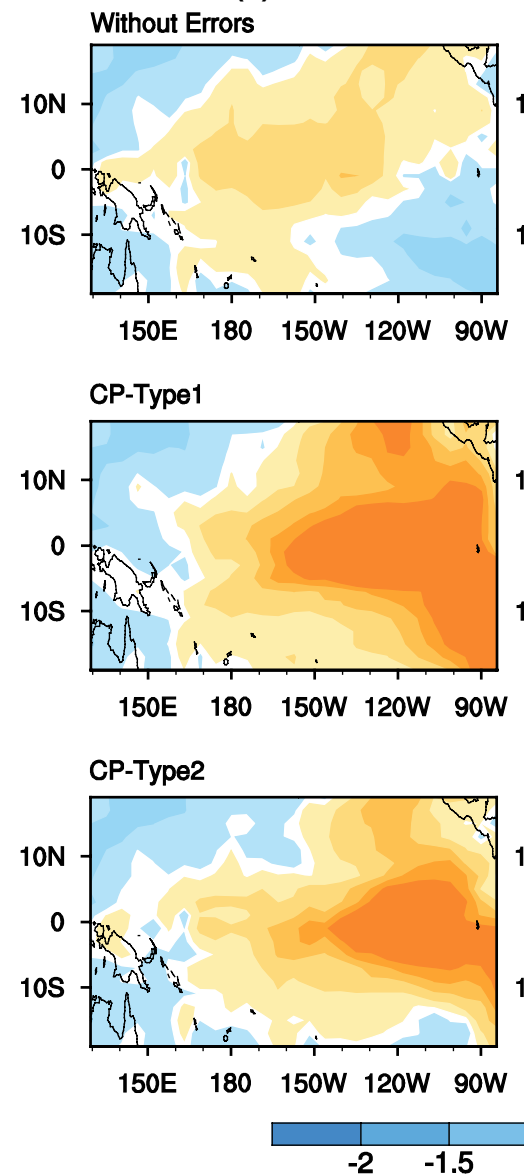

(b) 2002/03

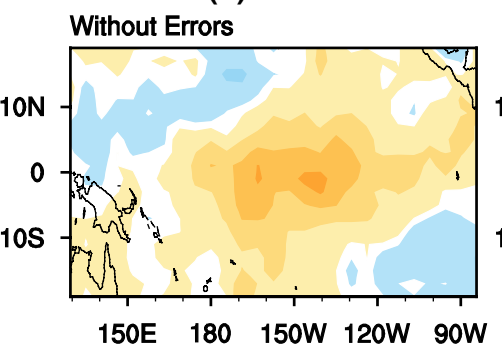

CP-Type1

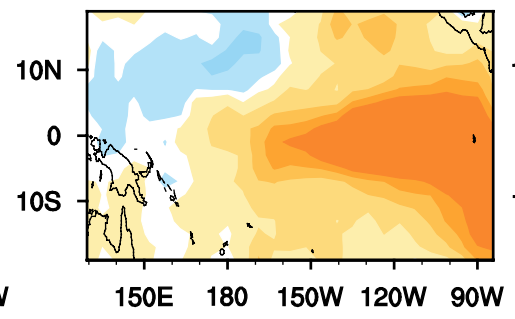

(c) $2004 / 05$

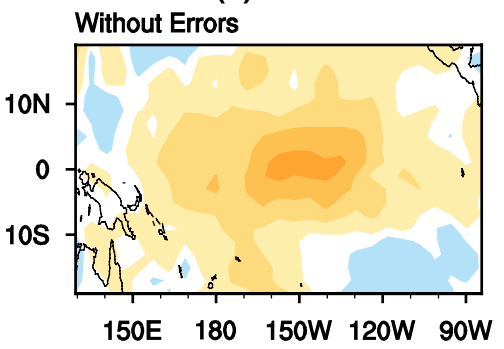

CP-Type1

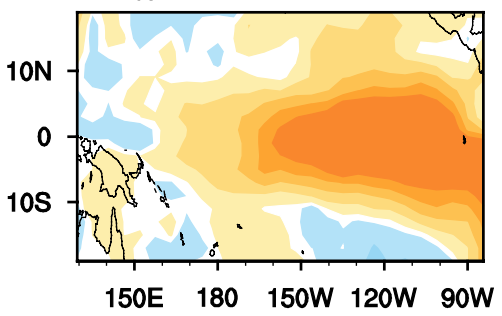

CP-Type2

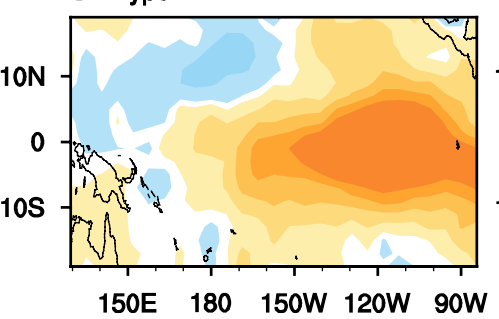

CP-Type2

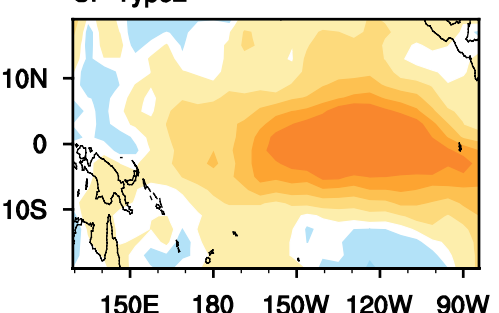

Fig. 5 Twelve month-lead predictions of SSTA of three CP-El Niño events (units are ${ }^{\circ} \mathrm{C}$ ), where the start month is January (0) and the initial conditions are without initial errors (top panel), and perturbed by both CP-type-1 errors (middle panel) and CP-type-2 errors (bottom panel). The CP-El Niño events are a 1990/1991, b 2002/2003, and c 2004/2005 
eastern equatorial Pacific and result in spurious EP-El Niño predictions for the CP- El Niño events.

From the above results, it is known that the CP-type-1 (and 2) errors have similar evolving mode whenever the predictions are initialized. Nevertheless, there exist differences among the magnitudes of prediction errors caused by CP-type-1 (and 2) errors when initialized at various start months; consequently, CP-type-1 (and -2) errors could have different season-dependent growth behavior for the predictions with different start months. To make it clear, we now explore the season-dependent evolution of the CNOP-type initial errors for CP-El Niño events. For each CP-El Niño event chosen in Sect. 2, we estimate the growth tendency of prediction errors caused by CNOPtype initial errors by calculating the slope $(\kappa)$ of the curve, $\gamma(t)=\left\|\vec{T}^{\prime}(t)\right\|_{2}$ in different seasons, as before. The results are shown in Fig. 6, which shows the ensemble mean of the seasonal growth tendency of prediction errors caused by the CP-type- 1 and 2 errors for three CP-El Niño events. The CP-type-1 errors tend to have significant growth in April-May-June and/or July-August-September, the most probable times for a prediction barrier to appear in an El Niño climate model. Note that although the largest growth of prediction errors appear in JulyAugust-September for predictions with start month January, the error growth during April-May-June has become aggressively large, which could have caused the dramatic decrease of El Niño forecast skill during April-May-June and occurred a significant SPB phenomenon (Mu et al. 2007a, b). In addition, for predictions made in April, Yu et al. (2012) argued that the predictions start directly in the spring, and the decrease of the forecast skill for El Niño events during either JAS or the OND season is the most dramatic, while the decrease seen during the spring (April-May-June) is not nearly as significant; in particular, the prediction errors at prediction time is not as large as those with other start months. From these we conclude that CP-type-1 errors yield a significant SPB for the tropical Pacific SSTA during CP-El Niño events. On the other hand, although large prediction errors are also generated by the CP-type-2 errors, the seasons with the largest prediction error growth tendencies are independent on start months. The growth of the prediction errors caused by the CP-type-2 errors does not phase-lock to any season; this implies that the CP-type-2 errors fail to result in a prominent SPB for CP-El Niño, despite generating a large prediction error.

\subsection{Eastern Pacific-El Niño events}

As described in the introduction, the CNOP-type initial errors for EP-El Niño events have been explored by tracing the growth of the optimal initial error of model El Niño events generated by the Zebiak-Cane model (Yu et al. 2009; Duan et al. 2009). Whether or not the CNOPtype initial errors, derived from model El Niño events, can be realized through observed El Niño events is questionable. To address this, we adopt the reproduced EP-El Niño events shown in Sect. 2 to investigate the CNOP-type initial errors of observed El Niño events.

For the three EP-El Niño events (1982/1983, 1987/1988 and 1997/1998), we also predict with a 12 month lead time, and start months of January (0), April (0), July (0), and October (0). We obtain a total 12 predictions for the three EP-El Niño events. For each of these EP-El Niño events, we calculate the corresponding CNOP-type initial error with an optimization time period of 12 months (i.e. a lead time of 12 months). When the predictions are initialized in July (0) and October (0) of each EP-El Niño event, the CNOP-type initial errors present an SSTA component with a zonal dipolar pattern, negative anomalies in the central western equatorial Pacific, positive anomalies in the eastern equatorial Pacific, and a consistently deepening thermocline depth across the equatorial Pacific. For predictions starting from January (0) and April (0), the CNOP-type initial errors exhibit an almost opposite pattern. Figure 7 shows the composite of two types of CNOP-type initial errors for three EP-El Niño events. For convenience, we denote the two types of CNOP-type errors as EP-type-1 and EP-type-2 error.

For EP-type-1 and 2 errors, we conduct numerical experiments similar to CP-type-1 and 2 errors,

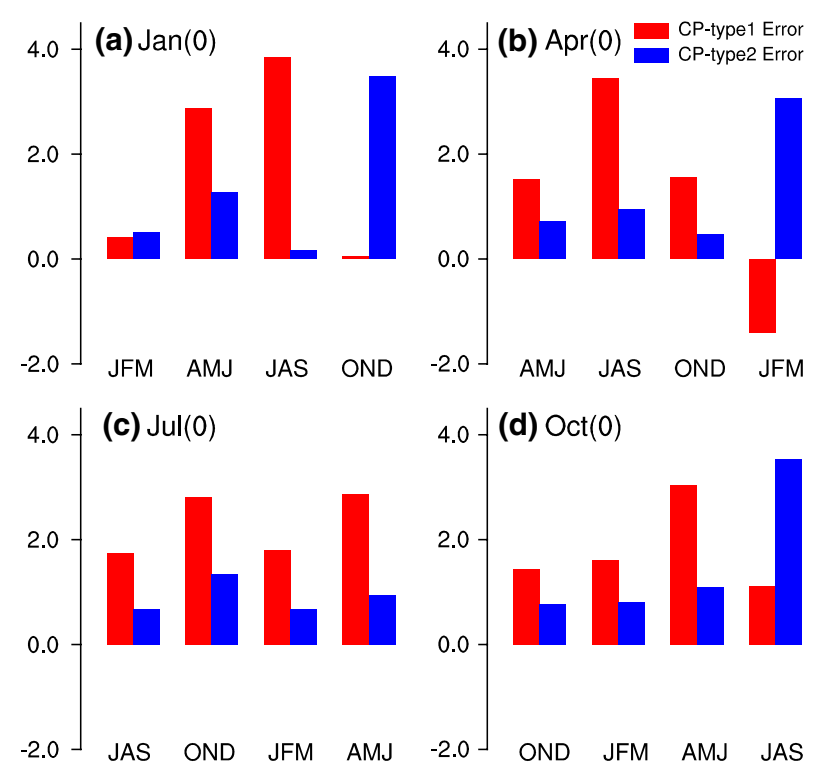

Fig. 6 Ensemble mean of seasonal growth tendency $\kappa$ of CP-type-1 and -2 errors for three CP-El Niño events, where both CP-type- 1 and -2 errors are superimposed on the start months a January (0), b April (0), c July (0) and d October (0), respectively 
(a) EP-type-1 CNOP error

SST Anomaly

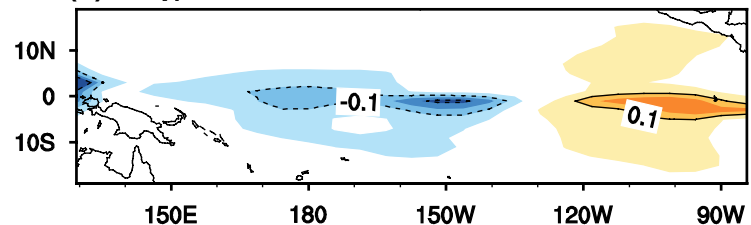

(b) EP-type-2 CNOP error

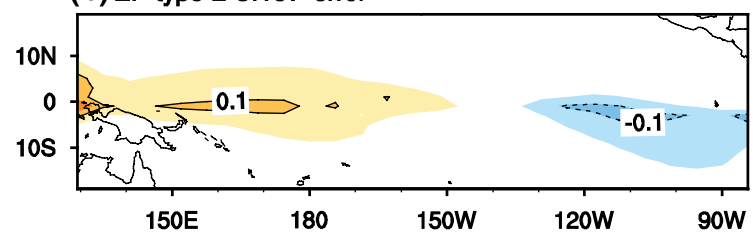

Thermocline Depth Anomaly
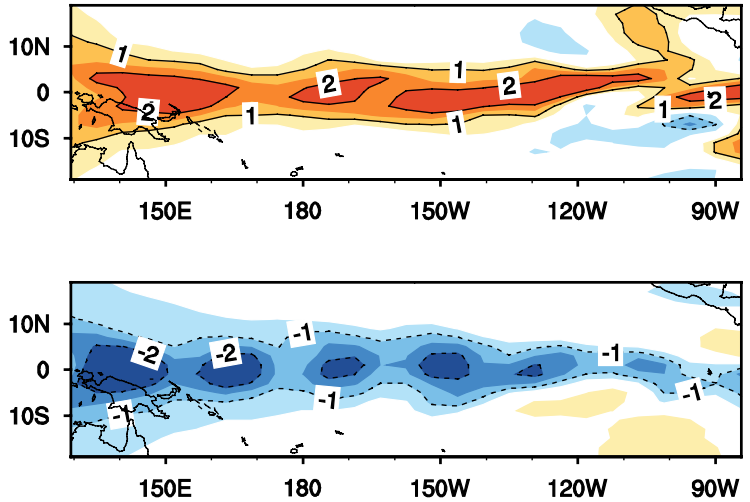

Fig. 7 Composite of a EP-type-1 and b EP-type-2 CNOP errors of three EP- El Niño events. The left column is the SSTA component (units are ${ }^{\circ} \mathrm{C}$; the contour interval is $0.1^{\circ} \mathrm{C}$ ), and the right column is the thermocline depth anomaly component (units are m; the contour interval is $1.0 \mathrm{~m}$ )

respectively. We notice that the EP-type-1 and 2 errors bear great resemblance with those derived from the model EP-El Niño events presented in Yu et al. (2009). Furthermore, both the EP-type-1 and 2 errors exhibit significant season-dependent growth, with the largest growth rate occurring in April-May-June and/or July-August-September (Fig. 8). That is to say, the EP-type- 1 and 2 errors, similar to the two types of CNOP errors of model El Niño events in Yu et al. (2009), also induce a significant SPB. The two types of CNOP errors for EP-El Niño events have almost opposite signs and, consequently, opposite growth behaviors (Fig. 9). This result demonstrates two dynamical mechanisms of error growth related to SPB: in one case, the errors grow in a manner similar to an EP-El Niño-like evolving mode and significantly overestimate the SSTA in spring, occurring the SPB; in the other, the errors develop more like a La Niña-like evolving mode, i.e. opposite to EP-El Niño (Fig. 9), which particularly offsets El Nino signal through spring significantly and yield aggressive SPB phenomenon. All the results derived from the reproduced EP-El Niño events are in agreement with those of Yu et al. (2009) and therefore support the CNOP-type initial errors obtained from model EP-El Niño events.

\subsection{Comparing the CNOP-type errors of two types of El Niño events}

Comparing the CNOP-type errors of EP-El Niño events (i.e. EP-type-1 and 2 errors) to those of CP-El Niño events (i.e. CP-type-1 and 2 errors), clearly shows that there are differences between them, not only in initial error spatial structure but also in related seasonal growth associated with SPB for tropical SSTAs. They also have some other aspects in common. Specifically, EP-type-1 errors and CP-type-1

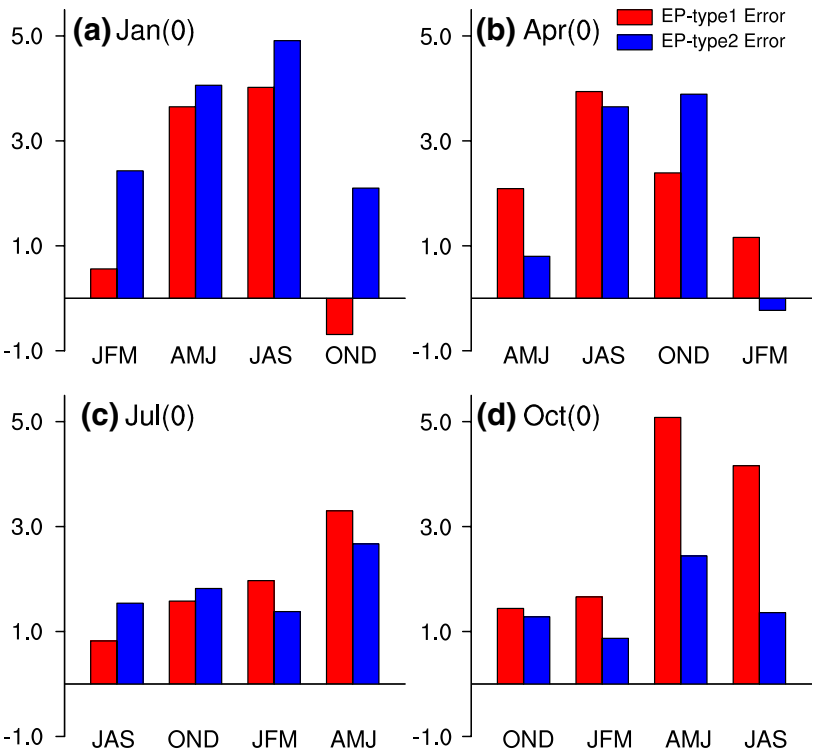

Fig. 8 Ensemble mean of seasonal growth tendency $\kappa$ of EP-type-1 and 2 errors for three EP-El Niño events, where both EP-type-1 and -2 errors are superimposed on the start months a January (0), b April (0), c July (0) and d October (0), respectively

errors are very similar (see Figs. 3a, 7a). Both exhibit an SSTA component with a zonal dipolar pattern, negative anomalies in the central western equatorial Pacific, and positive anomalies in the eastern equatorial Pacific, accompanied by a deepening thermocline depth across the equator. This is despite the fact that they correspond to different types of El Niño events. Furthermore, they both present an EP-El Niño-like evolving mode. The difference is that the CP-type-1 errors tend to predict CP-El Niño events as EP-El Niño-like events, while the EP-type-1 errors mainly cause the EP-El Niño events to be over-predicted. The CP-type-2 
(a) $1982 / 83$

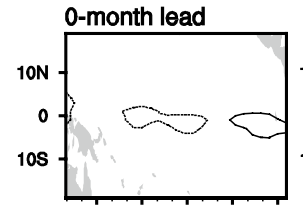

150E 180 150W120W 90W 3-month lead

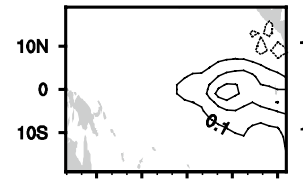

150E 180 150W120W 90W 6-month lead

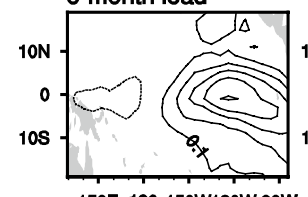

150E 180 150W120W 9OW 9-month lead

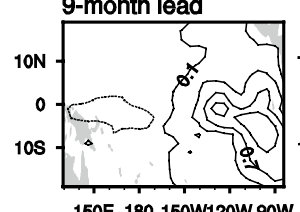

150E 180 150W120W 90W 12-month lead
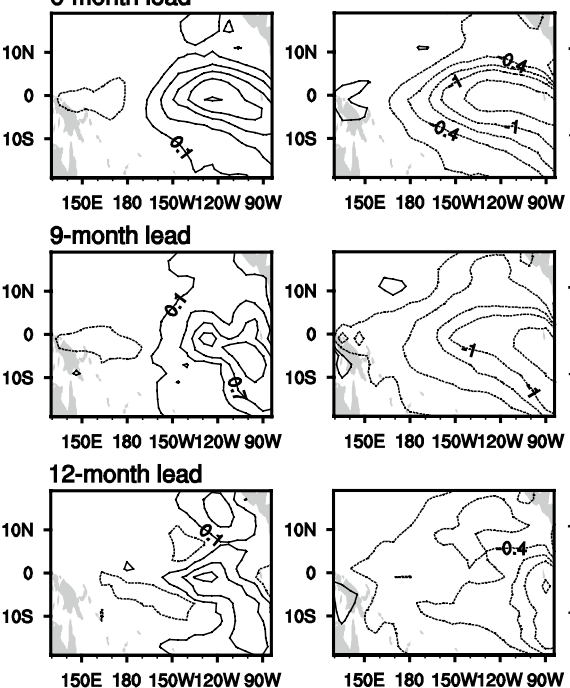

150E 180 150W120W 9OW

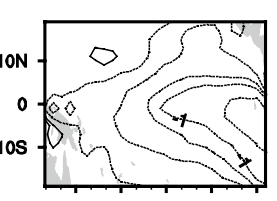

150E 180 150W120W 90W
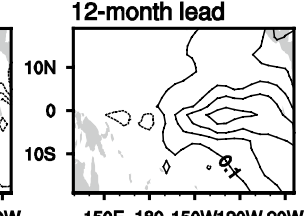

150E 180 150W120W 90W 9-month lead

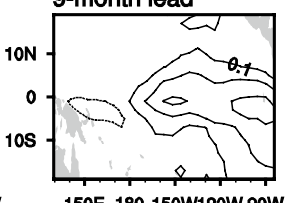

150E 180 150W120W 9OW -month lead

Fig. 9 Composite of the SSTA component of prediction errors caused by the EP-type-1 (left) and EP-type-2 (right) errors superimposed on three EP-El Niño events, a 1982/1983, b 1987/88, and c 1997/1998. For each El Niño event, the left column shows the com-

errors are different from the EP-type-2 errors. Furthermore, the CP-type- 2 errors present an evolving mode that initially experiences a process similar to a La Niña-like decay prior to a transition to growth phase of an EP-El Niño-like event. Despite this, we notice that the CP-type- 1 and 2 errors for CP-El Niño events and the EP-type-1 and 2 errors for EP-El Niño events present their largest errors in a common region: the central eastern equatorial Pacific and thermocline layer. The central eastern Pacific and thermocline layer may therefore represent a sensitive area for targeted observation of both EP- and CP-El Niño events. Reducing the errors in these regions may greatly improve the El Niño forecast skill. Since the corresponding CNOP-type errors play different roles in perturbing EP- and CP-El Niño events (i.e. the CNOP-type errors disturb the amplitude of EP-El Niño, but the spatial structure of CP-El Niño), we infer that reducing initial errors in these regions may also be helpful in predicting which type of El Niño event will occur. (c) $1997 / 98$

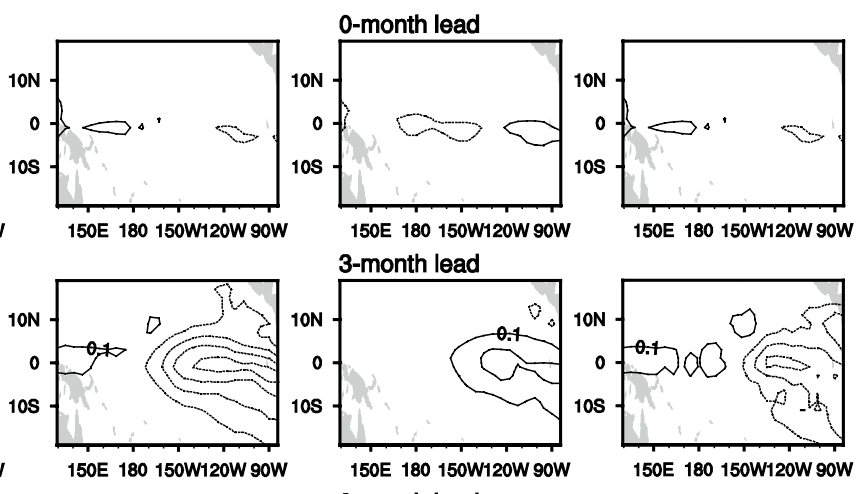

6-month lead
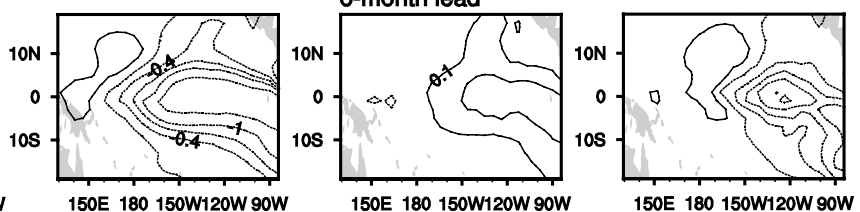

9 -month lead
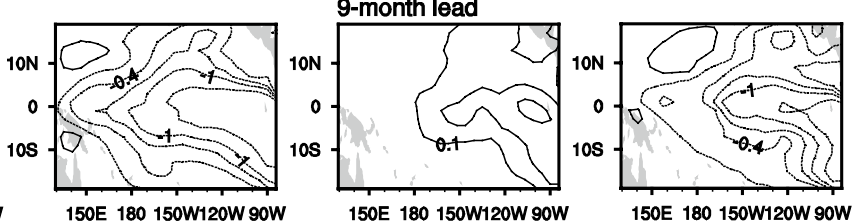

12-month lead
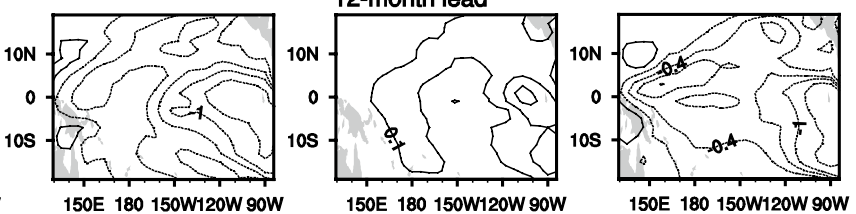

posite of prediction errors with start months being January (0), April (0), July (0) and October (0) caused by EP-type-1 errors while the right column illustrates those caused by EP-type- 2 errors (units: ${ }^{\circ} \mathrm{C}$ )

\section{Discussion}

We have shown that CP-type-1 and 2 errors tend to have an EP-El Niño-like evolving mode, quite different from the signal of the CP-El Niño events. In other words, the optimally growing initial errors for CP-El Niño events present different growth behavior than the CP-El Niño events themselves. However, $\mathrm{Mu}$ et al. (2014) argued that there exist great similarities between the optimal precursory disturbances and the optimally growing initial errors for EP-El Niño events. This indicates that when the errors have growth behavior similar to the signal, they may be optimal and have the largest effect on prediction uncertainties. We note that this conclusion is derived from EP-El Niño events. From the growth behavior of CP-type-1 and -2 errors shown in this study, it may show that such conclusion is not valid for CP-El Niño events. To make it sure, we choose initial errors having great similarities with initial 


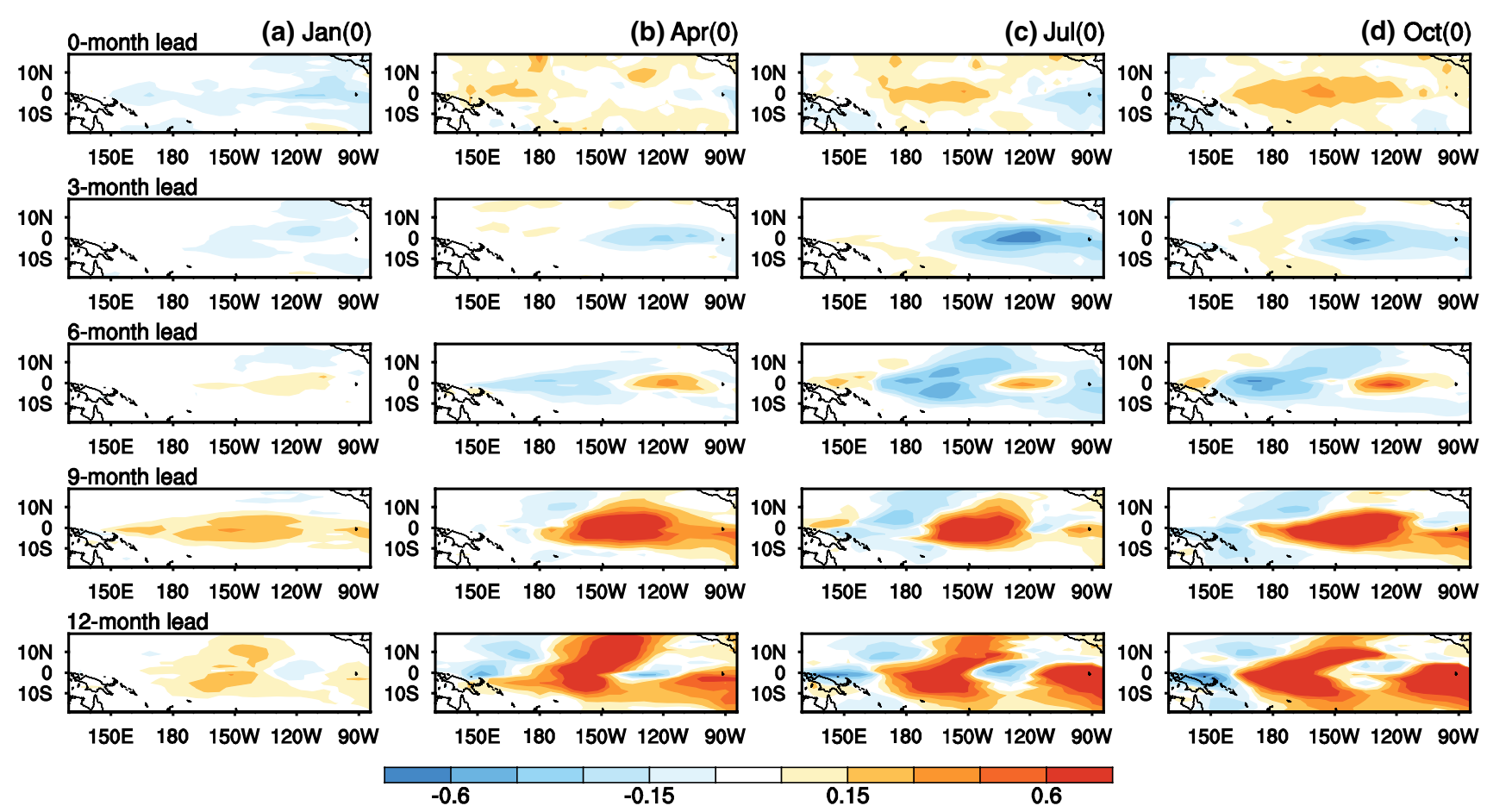

Fig. 10 Evolution of prediction errors caused by scaled initial errors for the 2004/2005 CP-El Niño, with the start months a January (0), b April (0), c July (0) and d October (0)

anomaly patterns for CP-El Nino events to explore whether or not such initial errors are optimally growing initial errors, compared to CP-type-1 and 2 errors.

The SSTA and thermocline depth anomalies of three CP-El Niño events in January (0), April (0), July (0), and October (0) are chosen and scaled to the same magnitude as the corresponding CNOP-type initial errors. Starting from January (0), April (0), July (0), and October (0) the model is integrated for 1 year, with the initial field set to the state value of the CP-El Niño events at the start month plus the corresponding scaled initial errors. Subtracting the CP-El Niño events from predictions obtained in this way yields information on the evolution of prediction errors of tropical SSTAs. Some of these initial errors, because they are extracted from signal of CP-El Niño events, do indeed develop into an SSTA pattern with a warming center in the central equatorial Pacific and have growth behavior similar to the CP-El Niño events (see Fig. 10). However, the resulting prediction errors for tropical Pacific SSTA are much smaller than those caused by the corresponding CNOP-type errors (see Fig. 11). Consequently, despite the initial errors having growth behavior similar to the signal of CP-El Niño events, they may not be the optimally growing initial errors for CP-El Niño events. Actually, our results show that an initial error exhibiting an EP-El Niñolike evolving mode represents the optimally growing initial error for CP-El Niño events. From observation, EP-El

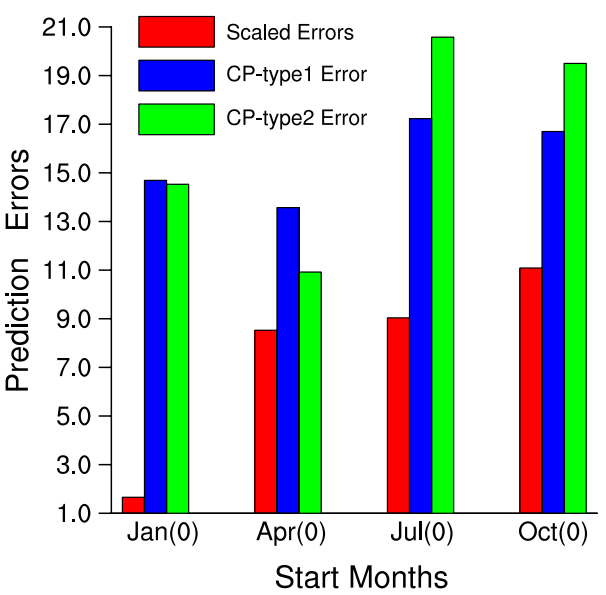

Fig. 11 The prediction errors of the tropical Pacific SSTA for the 2004/2005 CP-El Niño event caused by CP-type-1, CP-type-2, and scaled initial errors, where such three kinds of initial errors are initialized at the start months January (0), April (0), July (0), and October $(0)$ and related prediction errors are measured by $\left\|\vec{T}^{\prime}(\tau)\right\|_{2}=\sqrt{\sum_{i, j} w_{1} T_{i, j}^{\prime}(\tau)}$

Niño events are often more intense than CP-El Niño events, which may shed light on CP-type- 1 and 2 errors having an EP-El Niño-like evolving mode that causes much larger prediction errors than initial errors with a CP-El Niñolike evolving mode. The similarities between the optimal 
precursory disturbance and the optimally growing initial errors may not be valid for CP-El Niño events.

Hendon et al. (2009) showed that prediction uncertainties of tropical Pacific SST are often dominated by prediction errors in eastern equatorial Pacific, which makes it very difficult to identify CP-El Niño events in predictions. In this paper, we show that the CNOP-type errors for CP-El Niño events always have an EP-El Niño-like evolving mode; i.e. the prediction errors of SST for CP-El Niño events are mainly due to the prediction errors in eastern equatorial Pacific. Clearly, the result shown in the present study provides a theoretical interpretation to that of Hendon et al. (2009).

\section{Summary}

Using the Zebiak-Cane model, we investigate the SPB phenomenon for two types of observed El Niño events by tracing the evolution of CNOP-type errors, where CNOP-type errors are superimposed on El Niño events and act as the initial error with the biggest effect on the El Niño predictions. We show that for CP-El Niño events, two types of CNOP-type errors are found: CP-type- 1 and CP-type-2. The former has an SSTA pattern with negative anomalies in the central western equatorial Pacific and positive anomalies in the eastern equatorial Pacific, accompanied by a thermocline depth anomaly pattern with positive anomalies along the equator. The latter presents an SSTA pattern in the central eastern equatorial Pacific, with a dipole structure of negative anomalies in the east and positive anomalies in the west, and a thermocline depth anomaly pattern with a slight deepening along the equator. CP-type-1 error evolves like the growth phase of an EP-El Niño-like event and yields a significant SPB for the tropical SSTA associated with the CP-El Niño. For CP-type-2 error, there is initially a La Niña-like decay and then a transition to the growth phase of an EP-El Niño-like event. There is no season-dependent evolution evident, and no SPB. There exist initial errors that develop into an SSTA pattern with a warming center in central equatorial Pacific and have growth behavior similar to the reference state in CP-El Niño events. Their prediction errors for tropical Pacific SSTA are much smaller than those caused by the corresponding CNOP-type errors. Initial errors with growth behavior similar to CP-El Niño events may not grow optimally as initial errors for CP-El Niño events. The EP-El Niño events also present two types of CNOP errors: EP-type-1 errors are similar to the CPtype-1 errors, while EP-type-2 errors are almost opposite to EP-type-1 ones. These two types of CNOP errors are very similar to those in Yu et al. (2009); they have obvious season-dependent evolution, and yield significant a SPB for the tropical SSTA associated with EP-El Niño events. Using Zebiak-Cane model generated El Niño events, Mu et al. (2014) demonstrated that initial errors with growth behavior similar to EP-El Niño events grow optimally as initial errors for EP-El Niño. The present study also uses observed EP-El Niño events, confirming the fact that the EP-type-1 and 2 errors tend to have growth behavior similar to EP-El Niño and La Niña evolving modes, respectively.

Compared the CNOP-type errors for EP- and CP-El Niño events, the viewpoint that the initial errors with growth behavior similar to EP-El Niño events themselves are the optimally growing initials may not be valid for CP-El Niño events. For both CP- and EP-El Niño events, CNOP-type errors that cause a prominent SPB phenomenon mainly concentrate in central eastern equatorial Pacific and the thermocline layer. This implies that the prediction of both types of El Niño events may be sensitive to initial errors in these regions, and therefore that the regions may represent sensitive areas for targeted observation of the two types of El Niño events. By adding additional observations in the regions, the prediction skill for the two types of El Niño events may be greatly improved: this should be the subject of future studies. Hendon et al. (2009) recognized the importance of the accurate prediction of eastern Pacific SSTA in successful distinctions of two types of El Niño. This reflects the possibility that the two types of El Niño events have a common sensitive area.

We demonstrate two types of CNOP errors for EP- and CP-El Niño events, which have the most severe effect on prediction uncertainties. For EP-type event, both types of CNOP errors cause significant SPB for tropical SSTA, while for CP-type events, only one of the CNOP-type errors induces a significant SPB. The EP-El Niño predictions may be much more likely to encounter a SPB than the CP-El Niño predictions. In this sense, the CP-El Niño events may be more predictable than the EP-El Niño events, if the effect of model errors can be neglected. Hendon et al. (2009) also indicated that the predictive skill of the NINO4 index shows much less of a SPB, supporting the viewpoint presented in this study.

We did not consider La Niña events in this study, which Kug et al. (2009) and Kug and Ham (2011) showed are hard to separate into two types due to the similarity of SST patterns. We did not consider the effect of model errors either. How the model error affects the SPB for El Niño events, especially for CP-El Niño events, should be explored in-depth in future studies. It is currently unclear whether the characteristics of the initial errors that cause a significant SPB for the two types of El Niño events demonstrated in this study would hold. To determine this, the effect of the model errors on ENSO predictions should be studied. Furthermore, realistic hindcast experiments should be conducted to apply these theoretical results and examine their reliability. Although these questions are challenging, they are very important for improving ENSO 
forecast skill and it is expected that they can be resolved in future work.

Acknowledgments This work was jointly sponsored by the National Basic Research Program of China (Grant No. 2012CB417404), the National Public Benefit (Meteorology) Research Foundation of China (Grant No. GYHY201306018), and the National Natural Science Foundation of China (Grant Nos. 41176013 and 41230420).

Open Access This article is distributed under the terms of the Creative Commons Attribution 4.0 International License (http://creativecommons.org/licenses/by/4.0/), which permits unrestricted use, distribution, and reproduction in any medium, provided you give appropriate credit to the original author(s) and the source, provide a link to the Creative Commons license, and indicate if changes were made.

\section{Appendix}

\section{The optimal forcing vector approach (OFV)}

Consider a nonlinear partial differential equation:

$\left\{\begin{array}{l}\frac{\partial \mathbf{u}}{\partial t}=F(\mathbf{u}, t), \\ \left.\mathbf{u}\right|_{t=0}=\mathbf{u}_{0},\end{array}\right.$

where $\quad \mathbf{u}(x, t)=\left[u_{1}(\mathbf{x}, t), u_{2}(\mathbf{x}, t), \ldots, u_{n}(\mathbf{x}, t)\right] \quad$ is the state vector, $F$ is a nonlinear operator, $\mathbf{u}_{0}$ is the initial state, $(\mathbf{x}, t) \in \Omega \times[0, T], \Omega$ is a domain in $R^{n}, T<+\infty$, $\mathbf{x}=\left(x_{1}, x_{2}, \ldots, x_{\mathrm{n}}\right)$, and $t$ is the time. For the given initial field $\mathbf{u}_{0}$, the solution to Eq. (3) for the state vector $\mathbf{u}$ at time $\tau$ is given by

$\mathbf{u}(\mathbf{x}, \tau)=M_{\tau}\left(\mathbf{u}_{0}\right)$.

Suppose the model described by Eq. (3) is used to predict the motion of the atmosphere or oceans; however, the errors are associated with the model and then yield prediction uncertainties. Considering superimposing a time-variant external forcing to offset the model error effects, ones need to obtain a proper external forcing $\mathbf{f}(\mathbf{x}, t)$ for Eq. (5) to make the model agree with the observation.

$\left\{\begin{array}{l}\frac{\partial \mathbf{u}}{\partial t}=F(\mathbf{u}, t)+\mathbf{f}(\mathbf{x}, t), \\ \left.\mathbf{u}\right|_{t=0}=\mathbf{u}_{0} .\end{array}\right.$

Thus, this problem can be transferred into a type of nonlinear optimization problem. The optimization problem can consider that certain $\mathbf{f}(\mathbf{x}, t)$ are chosen such that the differences between the model simulation and the observations are minimized. That is, an external forcing should be chosen to satisfy the following optimization problem

$$
J\left(\mathbf{f}_{\min , t_{i}}\right)=\min \left\|M_{t_{i+1}-t_{i}}\left(\mathbf{f}_{t_{i}}\right)\left(\mathbf{u}_{t_{i}}\right)-\mathbf{u}_{t_{i+1}}^{o b s}\right\|,
$$

where $t_{i}, t_{i+1} \in\left[t_{0}, t_{k}\right], M_{t_{i+1}-t_{i}}\left(f_{t_{i}}\right)$ is the propagator of Eq. (5) from time $t_{i}$ to $t_{i+1}$ and $\mathbf{u}_{t_{i}}=M_{t_{i}-t_{i-1}}\left(f_{\min , t_{i-1}}\right)\left(\mathbf{u}_{t_{i-1}}\right)$. Note that the time interval $\left[t_{i}, t_{i+1}\right]$ is not necessary to be a time step of numerical integration, but may represent several days, a month, a season or others. An external forcing (vector) $\quad \mathbf{f}_{\min , t_{k}-t_{0}}=\left(f_{\min , t_{0}}, f_{\min , t_{1}}, f_{\min , t_{2}}, \ldots, f_{\min , t_{k-1}}\right)$ can be obtained from Eq. (6). This forcing vector $\mathbf{f}_{\min , t_{k}-t_{0}}$ is the OFV, which produces the model simulation closest to the observation during the time window $\left[t_{0}, t_{k}\right]$.

It is clear that for a given norm, Eq. (6) defines an unconstrained optimization problem, with the OFV $\mathbf{f}_{\min , t_{k}-t_{0}}$ being the minimum point of the objective function in the phase space. We note that the OFV is still time-independent during the time interval $\left[t_{i}, t_{i+1}\right]$. Therefore, the OFV can be computed as constant FSV proposed by Barkmeijer et al. (2003) by using the limited memory L-BFGS (Liu and Nocedal 1989) algorithm. This solver adopts the gradientsteepest descent method and finds the minimum value of an objective function, in which one needs to calculate the gradient of the objective function with respect to the external forcing. Feng and Duan (2013) provided the approach of numerically computing the gradient of the objective function with respect to the external forcing. We refer readers to the paper of Feng and Duan (2013) for the details of this approach. Using this gradient information, we can compute the OFV of a numerical model using the L-BFGS solver.

\section{References}

Ashok K, Behera SK, Rao SA, Weng HY, Yamagata T (2007) El Nino Modoki and its possible teleconnection. J Geophys Res 112:C11007. doi:10.1029/2006JC003798

Barber RT, Chavez FP (1983) Biological consequences of El-Nino. Science 222:1203-1210

Barkmeijer J, Iversen T, Palmer TN (2003) Forcing singular vectors and other sensitive model structures. Q J R Meteorol Soc 129(592):2401-2423

Birgin EG, Martınez JM, Raydan M (2000) Nonmonotone spectral projected gradient methods on convex sets. SIAM J Optim 10:1196-1211

Blumenthal MB (1991) Predictability of a coupled ocean-atmosphere model. J Clim 4:766-784

Cane MA (1983) Oceanographic events during El-Nino. Science 222:1189-1195

Chen DK, Cane MA (2008) El Nino prediction and predictability. J Comput Phys 227:3625-3640

Chen D, Zebiak SE, Busalacchi AJ, Cane MA (1995) An improved procedure for El Nino forecasting-implications for predictability. Science 269:1699-1702

Chen DK, Cane MA, Kaplan A, Zebiak SE, Huang DJ (2004) Predictability of El Nino over the past 148 years. Nature 428:733-736

Duan WS, Wei C (2012) The "spring predictability barrier" for ENSO predictions and its possible mechanism: results from a fully coupled model. Int J Climatol 33:1280-1292

Duan WS, Mu M, Wang B (2004) Conditional nonlinear optimal perturbations as the optimal precursors for El Nino-Southern 
Oscillation events. J Geophys Res 109:D23105. doi:10.1029/20 04JD004756

Duan WS, Liu XC, Zhu KY, Mu M (2009) Exploring the characteristic of initial errors that cause a significant "spring predictability barrier" for El Nino events. J Geophys Res 114:C04022. doi:10. 1029/2008JC004925

Duan WS, Tian B, Xu H (2014) Simulations of two types of El Nino events by an optimal forcing vector approach. Clim Dyn 43:1677-1692

Fan Y, Allen MR, Anderson DLT, Balmaseda MA (2000) How predictability depends on the nature of uncertainty in initial conditions in a coupled model of ENSO. J Clim 13:3298-3313

Feng F, Duan WS (2013) The role of constant optimal forcing in correcting forecast models. Sci China Earth Sci 56(3):434-443

Ham YG, Kug JS (2012) How well do current climate models simulate two types of El Nino? Clim Dyn 39:383-398

Hendon HH, Lim E, Wang G, Alves O, Hudson D (2009) Prospects for predicting two flavors of El Nino. Geophys Res Lett 36:L19713. doi:10.1029/2009GL040100

Jeong HI, Lee DY, Ashok K, Ahn JB, Lee JY, Luo JJ, Schemm JE, Hendon HH, Braganza K, Ham YG (2012) Assessment of the APCC coupled MME suite in predicting the distinctive climate impacts of two flavors of ENSO during boreal winter. Clim Dyn 39:475-493

Jin EK, Kinter JL, Wang B, Park CK, Kang IS, Kirtman BP, Kug JS, Kumar A, Luo JJ, Schemm J, Shukla J, Yamagata T (2008) Current status of ENSO prediction skill in coupled ocean-atmosphere models. Clim Dyn 31:647-666

Kao HY, Yu JY (2009) Contrasting eastern-Pacific and central-Pacific types of ENSO. J Clim 22:615-632

Kim ST, Yu JY, Kumar A, Wang H (2012) Examination of the two types of ENSO in the NCEP CFS model and its extratropical associations. Mon Weather Rev 140:1908-1923

Kug JS, Ham YG (2011) Are there two types of La Nina? Geophys Res Lett 38:L16704. doi:10.1029/2011GL048237

Kug JS, Jin FF, An SI (2009) Two types of El Niño events: cold tongue El Niño and warm pool El Niño. J Clim 22:1499-1515

Kug JS, Choi J, An SI, Jin FF, Wittenberg AT (2010) Warm pool and cold tongue El Nino events as simulated by the GFDL 2.1 coupled GCM. J Clim 23:1226-1239

Latif M, Barnett TP, Cane MA, Flugel M, Graham NE, von Storch H, Xu JS, Zebiak SE (1994) A review of ENSO prediction studies. Clim Dyn 9:167-179

Lim EP, Hendon HH, Hudson D, Wang G, Alves O (2009) Dynamical forecast of inter-El Nino variations of tropical SST and Australian spring rainfall. Mon Weather Rev 137:3796-3810. doi:10.11 75/2009MWR2904.1

Liu DC, Nocedal J (1989) On the limited memory method for large scale optimization. Math Program B 45:503-528

Luo JJ, Masson S, Behera SK, Yamagata T (2008) Extended ENSO predictions using a fully coupled ocean-atmosphere model. J Clim 21:84-93

McPhaden MJ (2003) Tropical Pacific Ocean heat content variations and ENSO persistence barriers. Geophys Res Lett 30:1480. doi:10.1029/2003GL016872

Moore AM, Kleeman R (1996) The dynamics of error growth and predictability in a coupled model of ENSO. Q J R Meteorol Soc 122:1405-1446

Mu M, Zhang Z (2006) Conditional nonlinear optimal perturbations of a two-dimensional quasigeostrophic model. J Atmos Sci 63:1587-1604
Mu M, Duan WS, Wang B (2003) Conditional nonlinear optimal perturbation and its applications. Nonlinear Process Geophys 10:493-501

Mu M, Duan WS, Wang B (2007a) Season-dependent dynamics of nonlinear optimal error growth and El Niño-Southern Oscillation predictability in a theoretical model. J Geophys Res 112:D10113. doi:10.1029/2005JD006981

Mu M, Xu H, Duan WS (2007b) A kind of initial perturbations related to "spring predictability barrier" for El Nino events in ZebiakCane model. Geophys Res Lett 34:L03709. doi:10.1029/200 6GL-27412

Mu M, Yu YS, Xu H, Gong TT (2014) Similarities between optimal precursors for ENSO events and optimally growing initial errors in El Niño predictions. Theor Appl Climatol 115:461-469

Powell MJD (1982) VMCWD: A FORTRAN subroutine for constrained optimization. DAMTP Report 1982/NA4, University of Cambridge, UK

Rasmusson EM, Carpenter TH (1982) Variations in tropical sea surface temperature and surface wind fields associated with the Southern Oscillation/El Nino. Mon Weather Rev 110:354-384

Rasmusson EM, Wallace JM (1983) Meteorological aspects of the El Nino/Southern Oscillation. Science 222:1195-1202

Rayner NA, Parker DE, Horton EB, Folland CK, Alexander LV, Rowell DP, Kent EC, Kaplan A (2003) Global analyses of sea surface temperature, sea ice, and night marine air temperature since the late nineteenth century. J Geophys Res 108(D14):4407. doi:10.1 029/2002JD002670

Samelson RM, Tziperman E (2001) Instability of the chaotic ENSO: the growth-phase predictability barrier. J Atmos Sci 58:3613-3625

Tang YM, Deng ZW, Zhou XB, Cheng YJ, Chen D (2008) Interdecadal variation of ENSO predictability in multiple models. J Clim 21:4811-4833

Webster PJ (1995) The annual cycle and the predictability of the tropical coupled ocean-atmosphere system. Meteorol Atmos Phys 56:33-55

Webster PJ, Yang S (1992) Monsoon and ENSO: selectively interactive systems. Q J R Meteorol Soc 118:877-926

Weng HY, Ashok K, Behera SK, Rao SA, Yamagata T (2007) Impacts of recent El Nino Modoki on dry/wet conditions in the Pacific rim during boreal summer. Clim Dyn 29:113-129

Xue Y, Cane MA, Zebiak SE, Blumenthal MB (1994) On the prediction of ENSO: a study with a low-order Markov model. Tellus 46:512-528

Xue Y, Cane MA, Zebaik SE (1997) Predictability of a coupled model of ENSO using singular vector analysis Part II: optimal growth and forecast skill. Mon Weather Rev 125:2043-2056

Yu JY, Kao HY (2007) Decadal changes of ENSO persistence barrier in SST and ocean heat content indices: 1958-2001. J Geophys Res 112:D13106. doi:10.1029/2006JD007654

Yu YS, Duan WS, Xu H, Mu M (2009) Dynamics of nonlinear error growth and season-dependent predictability of El Nino events in the Zebiak-Cane model. Q J R Meteorol Soc 135:2146-2160

Yu YS, Mu M, Duan WS, Gong TT (2012) Contribution of the location and spatial pattern of initial error to uncertainties in El Nino predictions. J. Geophy. Res. 117:C06018. doi:10.1029/20 11JC007758

Zebiak SE, Cane MA (1987) A model El Nino-Southern Oscillation. Mon Weather Rev 115:2262-2278 